\title{
Preliminary Investigation of Microplastic as a Vector for Heavy Metals in Bye-ma Salt Mine, Wukari, Nigeria
}

\author{
B. N. Hikon, ${ }^{\mathrm{a}, *}$, G. G. Yebpella ${ }^{\mathrm{a}}$, L. Jafiya ${ }^{\mathrm{b}}$, S. Ayuba ${ }^{\mathrm{a}}$ \\ ${ }^{a}$ Dept. of Chemical Sciences, Faculty of Pure and Applied Sciences, Federal University Wukari, Taraba State, Nigeria \\ ${ }^{b}$ Dept. of Chemistry, Faculty Sciences, Federal University Gashua, Yobe State, Nigeria
}

\begin{abstract}
This study is aimed at the preliminary investigation of microplastics as carrier of heavy metals pollution in surface sediment. Heavy metals concentration was determined by FAAS while microplastics characterization was analysed by ATR-FTIR spectrophotometer. The results obtained showed high level of lead $(\mathrm{Pb})$ concentrations which ranged from $21.37-32.80 \mathrm{mg} / \mathrm{kg}$ across the sampling sites while Cd has the least concentration between $0.04-0.80 \mathrm{mg} / \mathrm{kg}$. The concentration of $\mathrm{Pb}$ and $\mathrm{Cd}$ were above the USEPA permissible limit in sediment. The following absorption bands; $2978.19,1728.28$ and $1458.23 \mathrm{~cm}^{-1}$ with the functional groups; $\mathrm{C}-\mathrm{H}$ stretch, $\mathrm{C}=\mathrm{O}$ stretch and $\mathrm{CH}_{2}$ bend indicates the presence of Ethylene vinyl acetate (EVA) in site S2 and S4 respectively. Other microplastics found in the sampling sites are Nylon, Nitrile, Polycarbonate and Poly propylene. This indicates that there is identical distribution of the microplastics in the sampling sites. The quantities of microplastics isolated ranged from $8.11-8.16 \mathrm{~g}$ across the sites. Aquatic organisms fed on these polymeric materials because of their unique appearance. Hence, heavy metals adsorption will lead to higher concentrations on microplastics which could be ingested and lead serious complication in their intestine.
\end{abstract}

DOI:10.46481/jnsps.2021.259

Keywords: microplastics, sediment, aquatic, heavy metals, functional group.

Article History :

Received: 17 June 2021

Received in revised form: 26 July 2021

Accepted for publication: 23 August 2021

Published: 29 August 2021

(C)2021 Journal of the Nigerian Society of Physical Sciences. All rights reserved. Communicated by: Edward Anand Emile

\section{Introduction}

Water has faced series of challenges ranges from point and non point sources of pollution and these challenges have remained the same from time immemorial, the nature of pollution has evolved and lengthened over time. Freshwater biotas all over the planet earth are being endangered by both old and new form of pollutants. Plastic debris are found in seas, oceans and large body of festered water worldwide $[1,2]$ mostly constituted by organic pollutants such as microplastics. [3, 4]

\footnotetext{
${ }^{*}$ Corresponding author tel. no: $+234(0) 8065374951$

Email address: babahikon@fuwukari .edu.ng (B. N. Hikon )
}

defines microplastics as plastic constituent part smaller than 5 $\mathrm{mm}$ in size. The word "micro plastic" differs from upper limit of $0.5 \mathrm{~mm}$ to $5 \mathrm{~mm}$ (universally used), and a lesser limit of 1 $\mathrm{m}$ often used for practical purposes. However, groups of microplastics such as biofilms may penetrate and contribute to the sequestration of microplastics and metals in sediments [5, 6]. Microplastics are ingested by fish and other aquatic organisms when feeding in sediments. Once ingested, it results to problems like pseudo satiation, obstruction of the intestine, endocrine disorder through percolated plasticizers and contamination by adhered pollutants can arise [7,8]. One of the factors that sway the ingestion of the microplastics is "colour". Some sea debris has the colour that resemble that of their prey which 
entice raiders when ingested causes severe damage to the respiratory system of the aquatic organisms [9]. However, recent research by [10] showed that metal sorption kinetics fouling with organic and inorganic matter over time, increases the surface area and generating anionic active sites of the microplastics for the adsorption of metals from sediment [11].

The hydrophobic nature of the microplastics attract persistent organic pollutants and accumulate heavy metals like cadmium (cd), copper $(\mathrm{Cu})$, iron $(\mathrm{Fe})$, silver $(\mathrm{Ag})$, manganese $(\mathrm{Mn})$, aluminum $(\mathrm{Al})$ zinc $(\mathrm{Zn})$ and lead $(\mathrm{Pb})$, which could lead to a greater bio-accessibility of metals when aquatic animals consume micro plastics [12].

This research is aimed at isolation and characterization of microplastics in sediment as carrier of heavy metals in an aquatic system.

\section{Materials and Methods}

\subsection{Study Area}

The study area covers Bye-ma, former salt mine pond under Chonku ward but presently Hospital ward Wukari Local Government of Taraba State, Nigeria. Presently, the pond is used for fishing. It is located between longitudes $7^{\circ} 51^{\prime} 0^{\prime \prime}$ North and $9^{\circ} 47^{\prime} 0^{\prime \prime}$ East of the Greenwich meridian. Wukari Local Government area is situated in the southern part of Taraba State and it is about two hundred kilometers away from Jalingo the state capital. The Local Government is bounded by Plateau State in the North, Benue State in the Southwest. It has an area of about $4308 \mathrm{~km}^{2}$ (1663 sq mi).

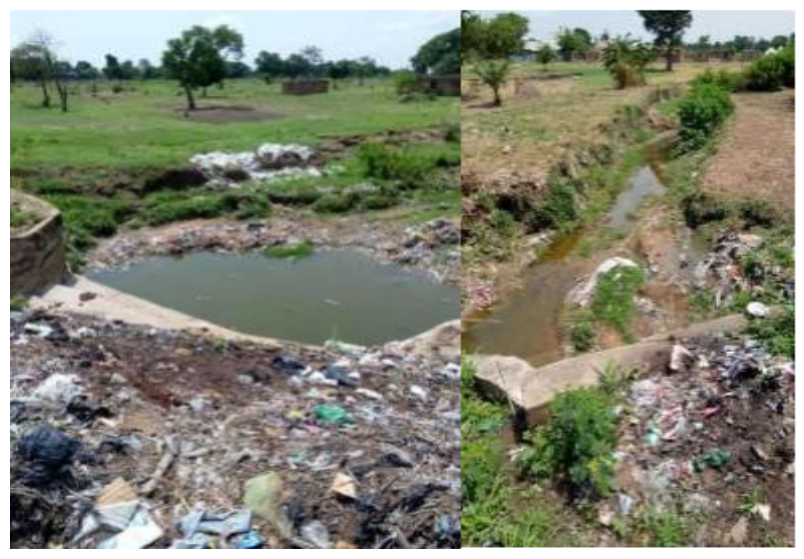

Figure 1. showing the study area (bye-ma pond)

\subsection{Sample Collection}

About four sampling sites were randomly mapped out for sediment samples collection, and were designated as S1, S2, S3 and $\mathrm{S} 4$ representing sites 1, 2, 3 and 4 respectively. The sampling sites were $50 \mathrm{~m}$ apart. Each site was further subdivided into four giving a total of sixteen sites. A $100 \mathrm{~g}$ each of the sediment samples were collected from the sampling sites in the month of March, 2020. The samples were collected with the aid of a stainless steel hand trowel at the depth of $0-15 \mathrm{~cm}$ into clean glass container that was previously washed in $1 \% \mathrm{HCl}$ and transported to the laboratory. The sediment samples from each sub sites were bulked together and mixed thoroughly to achieve homogeneity of the representative sample.

\subsection{Sample Preparation}

The samples were air-dried in the laboratory for two days, manually sorted out debris of large size above $5 \mathrm{~mm}$ mesh size. A set of four sieves with mesh sizes $8,5,1$ and $0.3 \mathrm{~mm}$ was obtained from Soil Science laboratory for the separation of particles size. Sediment samples were then sieved mechanically to obtain a fraction of $0.3 \mathrm{~mm}$. The sediment samples were divided into two portions (for heavy metal determination and isolation of microplastics) and are stored in glass bottles at room temperature until ready for further analysis.

\subsection{Extraction, Isolation and characterization of Microplas- tics from Sample Matrix}

Sediments samples collected on the $0.3 \mathrm{~mm}$ sieve are subjected to Wet Peroxide Oxidation (WPO) in the presence of a $\mathrm{Fe}$ (II) catalyst to digest labile organic matter. A $6 \mathrm{~g}$ of salt $(\mathrm{NaCl})$ to the mixture to increase its density of the aqueous solution according to [13]. Microplastics were floated on the surface of the solution, were filtered, dried and manually sorted out and characterized with ATR-FTIR spectrophotometer: model 630 Agilent Tech USA.

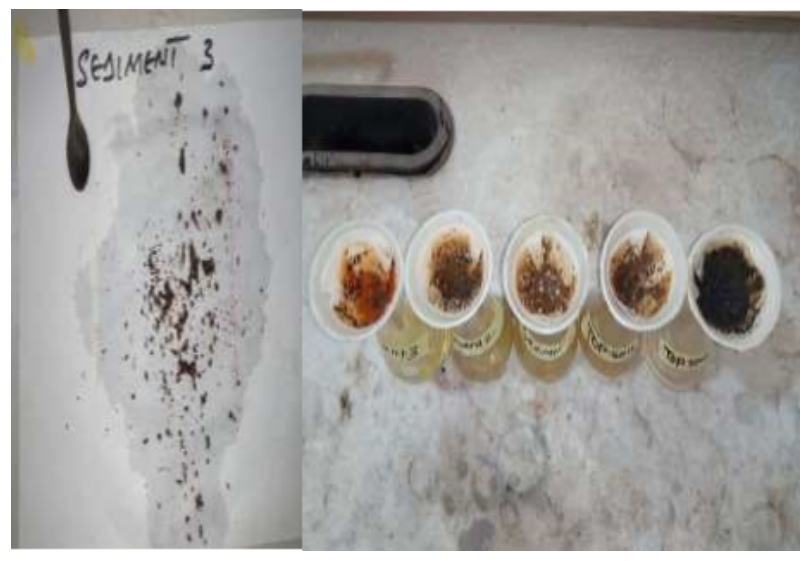

Figure 2. Micro plastics displayed on filtration apparatus

\subsection{Determination of Total Mass of Micro Plastics}

An empty vial was weighed and labelled A, the identifiable micro plastics was transferred to the vial and then reweighed $\mathrm{B}$. The mass of the isolated micro plastics $\mathrm{C}$ was determined by subtracting the mass of A from B (Formula: $B-A=C$ ). This procedure was repeated for all sediment samples [13]. 


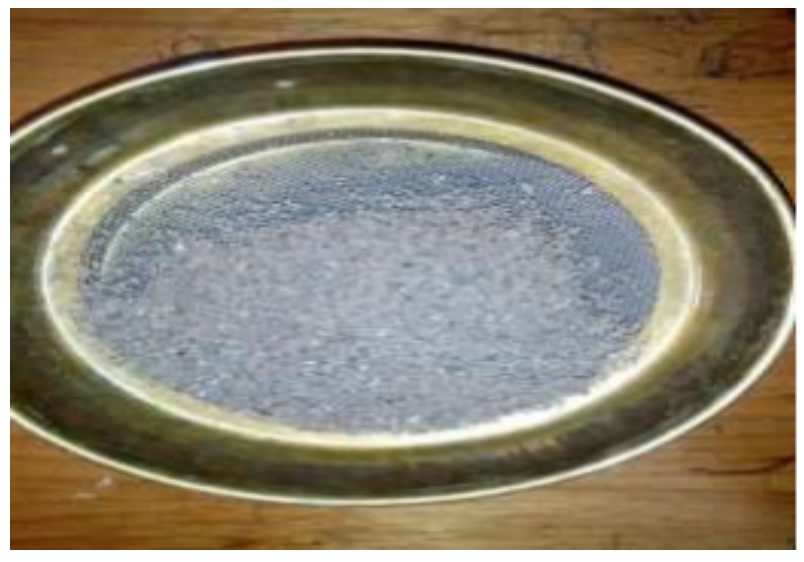

Figure 3. Micro plastics on sieve $0.3 \mathrm{~mm}$.

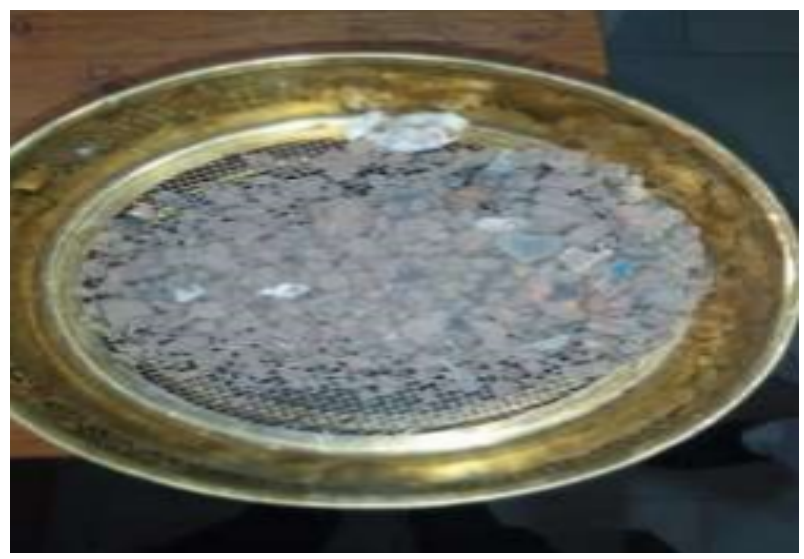

Figure 4. Retained debris/macroplastics on sieve $8 \mathrm{~mm}$

\subsection{Determination Heavy Metal Concentrations in Microplas- tics}

Method of heavy metals determination was adopted from [10] with little modifications. A $1.0 \mathrm{~g}$ of dried $0.3 \mathrm{~mm}$ size fraction of the microplastics sample were weighed into a beaker and digested with $25 \mathrm{~mL}$ mixture of analytical grade acids $\mathrm{HNO}_{3}: \mathrm{HC}$ in the ratio 3:1. The digestion was performed at a temperature of about $90^{\circ} \mathrm{C}$ for 30 minutes in a fume cupboard until clear solutions was obtained. Digested samples were allowed to cooled, filtered into a $100 \mathrm{~mL}$ volumetric flask, and made up to the mark with deionized water. Digests were analyzed by Flame Atomic Absorption Spectrometry (FAAS, Spectra AA 50, VARIAN). Triplicate determinations were made.

The actual concentrations of heavy metals were calculated from the formula below:

$$
\text { conc. }(m g / k g)=\frac{\text { conc. }(m g / l)}{\text { weight of sample digested }} \times \text { dilution volume }(1)
$$

\section{Result and Discussion}

\subsection{Accumulation of Heavy Metals on Microplastics}

The result obtained from the determination of heavy metals; Lead $(\mathrm{Pb})$, Cadmium $(\mathrm{Cd})$, Zinc $(\mathrm{Zn})$ and Copper $(\mathrm{Cu})$ in micro plastics from four different samples were shown in Table $1 . \mathrm{Pb}$ and $\mathrm{Cu}$ have the highest concentration level in all the samples while Cadmium has the least concentration and ranged from $0.040 .80 \mathrm{mg} / \mathrm{kg}$ compared to other metals. The high concentration of $\mathrm{Pb}$ which ranged from $21.37-32.80 \mathrm{mg} / \mathrm{kg}$ could be attributed to the following activities along the sampling sites; panel beating, automobile repairs, and discharge of lead from paints factories, lead acid accumulator cells and other dried cells. These wastes are released into water bodies by run off and atmospheric deposition.

This agreed with the work of [14] who reported that, high level of heavy metals in sediment is associated with anthropogenic activities. The results presented in this study noticeably indicate a high affinity of metals in solution to microplastics in the sediment. The concentrations of $\mathrm{Zn}$ and $\mathrm{Cu}$ in all the sites are within the permissive level by the United State Environmental Protection Agency (USEPA). This concentration level is by far less than the permissible limit for zinc concentration in sediment which range from $50-300$ and $20 \mathrm{mg} / \mathrm{kg}$. Zn present in the area could be as a result of its natural abundance, its association with Cadmium and as a result of mechanical abrasion of crushing/grinding [15]. Cadmium concentrations in all the sites were above the [16] permissible limit of $0.03-0.3 \mathrm{mg} / \mathrm{kg}$ in sediment. Cadmium is emitted to air by mines, metal smelters and industries using cadmium compounds for alloys, batteries, pigments and in plastics. All the concentrations of lead were above the permissible limit of $2-20 \mathrm{mg} / \mathrm{kg}$ as stated by [16]. $[12,10]$ and environmental monitoring [17] have indicated that microplastics accumulate metals in aquatic environment. Metal ions or complexes interact directly with the charged or neutral sites of the surface of the microplastic, and co-precipitate with or sorption onto hydrous oxides [12].

\subsection{Mass of micro plastics}

Figure 5 shows the quantities of microplastics recovered from each of the sampling sites after peroxide oxidation. S1 has the highest level of microplastics $(8.16 \mathrm{~g})$, followed by S4 which has $8.14 \mathrm{~g}$ and $\mathrm{S} 3$ with $8.13 \mathrm{~g}$ while $\mathrm{S} 2$ has $8.11 \mathrm{~g}$ respectively. The quantity and colors of microplastics normally draws the attention of aquatic organisms. [9] reported that aquatics animals sees plastic materials as prey and when ingested it could results to complications in their digestive system.

\subsection{Characterization of Microplastics}

Table 2 below showed the types and the various absorption bands of polymer materials identified in S1. Micro polymeric constituents discovered are polycarbonate and nylon (polyamide). Nylon is one of the common polymer material found in storage sack, thread for shoe sawing etc. Plastics aptitude to adsorb other pollutants makes them a potential trajectory for transferring other pollutants to the aquatic ecosystems, such as heavy metals. Both plastics and these pollutants are very difficult to degrade in the environment $[18,19]$.

The absorption spectrum of S1 displayed in Table 2 above, showed that Polycarbonate was detected within the following absorption bands: $678.97 \mathrm{~cm}^{-1}, 1519.96 \mathrm{~cm}^{-1}, 1712.85 \mathrm{~cm}^{-1}$ 
Table 1. Mean Concentration of Heavy Metals $(\mathrm{mg} / \mathrm{kg})$

\begin{tabular}{lcccc}
\hline \hline $\begin{array}{l}\text { Heavy Metals / } \\
\text { Sample Locations }\end{array}$ & $\mathrm{Pb}$ & $\mathrm{Cd}$ & $\mathrm{Zn}$ & $\mathrm{Cu}$ \\
\hline \hline S1 & $30.79 \pm 0.006$ & $0.05 \pm 0.006$ & $0.32 \pm 0.006$ & $1.33 \pm 0.003$ \\
S2 & $24.68 \pm 0.003$ & $0.04 \pm 0.002$ & $1.03 \pm 0.006$ & $1.45 \pm 0.002$ \\
S3 & $21.37 \pm 0.002$ & $0.80 \pm 0.003$ & $0.55 \pm 0.006$ & $1.32 \pm 0.003$ \\
S4 & $32.80 \pm 0.007$ & $0.50 \pm 0.007$ & $0.55 \pm 0.006$ & $1.73 \pm 0.003$ \\
USEPA 2002 & $2-20$ & $0.003-0.3$ & $50-300$ & 20 \\
\hline \hline
\end{tabular}

Table 2. FTIR Result for S1

\begin{tabular}{cccc}
\multicolumn{4}{c}{ Table 2. FTIR Result for S1 } \\
\hline \hline ABSORPTION BANDS $\left(\mathrm{cm}^{-1}\right)$ & RANGE & FUNCTIONAL GROUPS & POLYMER TYPE \\
\hline \hline 678.97 & $630-750$ & $\mathrm{C}=\mathrm{O}$ bending & \\
1519.96 & $1500-1550$ & Aromatic ring stretch & Polycarbonate \\
1712.85 & $1706-1730$ & $\mathrm{C}=\mathrm{O}$ stretching & \\
1519.96 & $1500-1550$ & N-H bend & \\
3248.23 & $3200-3550$ & N-H bend & \\
2985.91 & $2800-3000$ & C-H stretch & Nylon (polyamide) \\
2862.46 & $2800-3000$ & C-H stretch & \\
3340.82 & $3584-3700$ & C=O stretch & \\
\hline
\end{tabular}

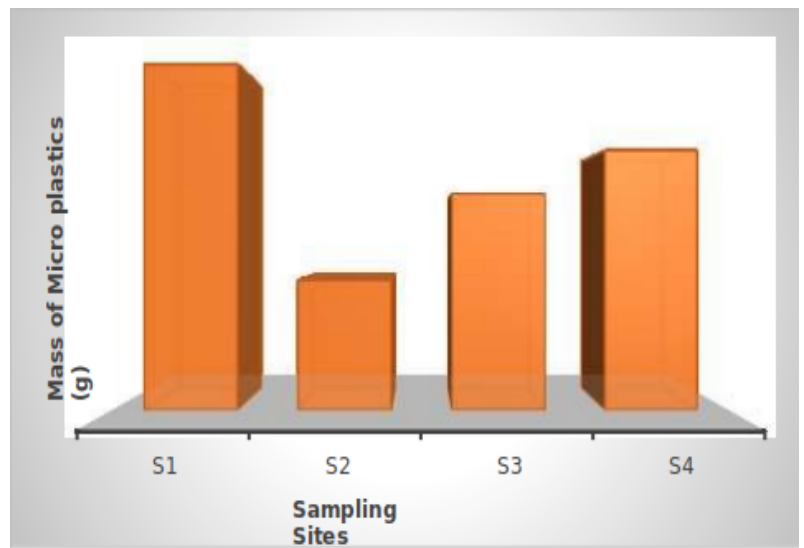

Figure 5. Quantity of microplastic in each sampling sites

and $1519.96 \mathrm{~cm}^{-1}$ with the functional groups: $\mathrm{C}=\mathrm{O}$ bending, Aromatic ring stretch, $\mathrm{C}=\mathrm{O}$ stretching and $\mathrm{N}-\mathrm{H}$ bend respectively while Nylon (polyamide) was detected within the bands: $2985.91 \mathrm{~cm}^{-1}, 2862.46 \mathrm{~cm}^{-1}$ and $3340.82 \mathrm{~cm}^{-1}$ with the following functional groups: $\mathrm{C}-\mathrm{H}$ stretch, $\mathrm{C}=\mathrm{O}$ stretch and $\mathrm{N}-\mathrm{H}$ bend. Nylons are made from organic (carbon based) found in natural materials such as coal or petroleum, it can also be got from renewable materials called Zytel. Polycarbonates are made from the condensation of carbonic acid and Bisphenol A. These materials after usage are disposed into water ways. Because of their non degradable nature they remain in the environment and are finally deposited in soil, water and eventually accumulate in the sediment.

The results obtained for FTIR analysis in Table 3 showed that only Ethylene vinyl acetate (EVA) polymers are predom- inant in sample S2. Ethylene vinyl acetate (EVA) has the following absorption bands and functional groups: $2978.19 \mathrm{~cm}^{-1}$, $1728.28 \mathrm{~cm}^{-1}$ and $1458.23 \mathrm{~cm}^{-1}$ respectively (C-H stretch, $\mathrm{C}=\mathrm{O}$ stretch and $\mathrm{CH} 2$ bend).

The result of microplastics characterization for sample S3 as showed in Table 4 indicates that absorption occurred at the following frequencies: $2916.47 \mathrm{~cm}^{-1}, 2244.91 \mathrm{~cm}^{-1}, 1458.23$ $\mathrm{cm}^{-1}$ and $941 \mathrm{~cm}^{-1}$ with functional groups: $\mathrm{C}-\mathrm{H}$ stretch, $\mathrm{C} \equiv \mathrm{N}$ stretch, $\mathrm{C}=\mathrm{C}$ stretch and $=\mathrm{C}-\mathrm{H}$ str. This absorption band and functional groups represent Nitrile polymeric constituent. Consequently, absorption bands at 2916.47, 1458.23 and 941.29 $\mathrm{cm}^{-1}$ which give the following functional groups $(\mathrm{C}-\mathrm{H}$ stretch, $\mathrm{CH}_{2}$ bend, $\mathrm{C}-\mathrm{H}$ bend and $\mathrm{CH}_{3}$ bend) indicates the presence of Poly propylene in the sample.

The absorption bands obtained for sample $\mathrm{S} 4$ as displayed in Table 5 above showed that ethylene vinyl acetate (EVA) is present in the sample. Hence, it indicates that the absorption band of Ethylene vinyl acetate (EVA) in S2 (Table 3) correspond with that of S4 in Table 5. This indicates that there is equal distribution of the microplastics debris in the sampling sites.

\section{Conclusion}

In the present study, a preliminary assessment of microplastics pollution in the surface sediments from Bye-ma salt mine pond was obtained. The results of flame atomic absorption spectrometer and FTIR showed that microplastics are carriers of heavy metals since considerable concentrations of these metals, $\mathrm{Pb}$ and $\mathrm{Cu}$ were determined from the plastics materials. However, the polymer materials discovered are Nylon, Nitrile, 
Table 3. FTIR Result for S2

\begin{tabular}{cccc}
\hline \hline ABSORPTION BANDS $\left(\mathrm{cm}^{-1}\right)$ & RANGE & FUNCTIONAL GROUPS & POLYMER TYPE \\
\hline \hline 2978.19 & $2800-3000$ & C-H stretch & \\
1728.28 & $1706-1730$ & C=O stretch & Ethylene vinyl acetate (EVA) \\
1458.23 & $1430-1470$ & CH2 bend & \\
\hline \hline
\end{tabular}

Table 4. FTIR Result for S2

\begin{tabular}{cccc}
\hline \hline ABSORPTION BANDS $\left(\mathrm{cm}^{-1}\right)$ & RANGE & FUNCTIONAL GROUPS & POLYMER TYPE \\
\hline \hline 2916.47 & $2800-3000$ & $\mathrm{C}-\mathrm{H}$ stretch & \\
2264.91 & $2260-2320$ & $\mathrm{C} \equiv \mathrm{N}$ stretch & Nitrile \\
941.29 & $900-950$ & $=\mathrm{C}-\mathrm{H}$ str & \\
2916.47 & $2800-3000$ & $\mathrm{C}-\mathrm{H}$ stretch & \\
1458.23 & $1430-1470$ & $\mathrm{CH}_{2}$ bend & Poly propylene \\
941.29 & $900-950$ & $\mathrm{CH}_{3}$ bend & \\
\hline \hline
\end{tabular}

Table 5. FTIR Result for S2

\begin{tabular}{cccc}
\hline \hline ABSORPTION BANDS $\left(\mathrm{cm}^{-1}\right)$ & RANGE & FUNCTIONAL GROUPS & POLYMER TYPE \\
\hline \hline 2924.18 & $2800-3000$ & C-H stretch & \\
2862.46 & $2800-3000$ & C-H stretch & Ethylene vinyl acetate (EVA) \\
1735.99 & $1706-1730$ & $\mathrm{C}=\mathrm{O}$ stretch & \\
\hline & & & \\
1458.23 & $1430-1470$ & $\mathrm{CH}_{2}$ bend & Polyethylene terephthalate \\
\hline \hline
\end{tabular}

EVA and Poly propylene. Sediments are reservoir for both microplastics and heavy metals. Aquatic organisms depend on sediment materials for survival as such there will be high concentration of these metals in aquatic animals and this will directly affect the food chain.

\section{Acknowledgement}

The Authors wish to acknowledge the support of Mr. Godfrey N. S and Mr. Peter Ujulu of Federal University Wukari for proof reading of the manuscript.

\section{References}

[1] D.K. Barnes, F. Galgani, R.C. Thompson \& M. Barlaz, "Accumulation and fragmentation of plastic debris in global environments", Philos. Trans. R. Soc., B 364 (2009) 1985. http://dx.doi.org/10.1098/rstb.2008.0205

[2] J.G. Derraik, " The pollution of the marine environment by plastic debris: a review”, Mar. Pollut. Bull. 44 (2002) 842.

[3] A.L. Andrady, " Microplastics in the marine environment", Marine Pollution Bulletin 62 (2011) 1596. http://dx.doi.org/10.1016/j.marpolbul.2011.05.030

[4] M. Cole, P. Lindeque, E. Fileman, C. Halsband, R. Goodhead, J. Moger \& T.S Galloway, “ Microplastic Ingestion by Zooplankton”, Environmental Science and Technology 46 (2012) 11327. http://books.google.com.ng

[5] E.L. Teuten, J.M. Saquing, D.R. Knappe, M.A. Barlaz, S. Jonsson, A. Björn, S.J. Rowland, R.C. Thompson, T.S. Galloway, R. Yamashita \& D. Ochi, " Transport and release of chemicals from plastics to the environment and to wildlife", Philos. Trans. R. Soc. 364 (2009) 2027.

[6] M. Long, B. Moriceau, M. Gallinari, C. Lambert, A. Huvet, J. Raffray \& P. Soudant, "Interactions between microplastics and phytoplankton aggregates: Impact on their respective fates", Mar. Chem. 175 (2015) 39. http://dx.doi.org/10.1016/j.marchem.2015.04.003

[7] S.L. Wright, D. Rowe, R.C. Thompson. \& T.S. Galloway, " Microplastic ingestion decreases energy reserves in marine worms", Curr. Biol. 23 (2013) 3031. http://doi.org/10.1016/j.cub.2013.10.068

[8] D. Lithner, A. Larsson \& G. Dave, " Environmental and health hazard ranking and assessment of plastic polymers based on chemical composition", Sci. Total Environ. 409 (2011) 3309. doi: 10.1016/j.scitotenv.2011.04.038

[9] M.L. Moser \& D.S. Lee, “ A Fourteen Year Survey of Plastic Ingetion by Western North Atlantic Seabirds", Colonial Waterbirds 15 (1992) 83. http://.doi.org/10.2307/1521357

[10] L. Holmes, A. Turner \& R.C. Thompson, “ Adsorption of trace metals to plastic resin pellets in the marine environment", Environ. Pollut. 160 (2012) 42. http://dx.doi.org/10.1016/j.envpol.2012.08.052

[11] D.D. Deheyn \& M.I. Latz, " Bioavailability of metals along a contamination gradient in San Diego Bay (California, USA)”, Chemosphere 63 (2006) 818. http:// dx.doi.org/10.1016/j.chemosphere.2005.07.066

[12] K. Ashton, L. Holmes, \& A. Turner, "Association of metals with plastic production pellets in the marine environment", Mar. Pollut. Bull. 60 (2010) 2050. http:// dx.doi.org/10.1016/j.marpolbul.2010.07.014.

[13] J. Masura, B. Joel, F. Gregory, A. Courtney \& H. Carlie, “ Laboratory Methods for the Analysis of Microplastics in the Marine Environment Recommendations for quantifying synthetic particles in waters and sediments", NOAA Technical Memorandum NOS-OR\&R-48. USA. (2015) 13.

[14] E.I. Uwah, N.P. Ndahi \& V.O. Ogugbuaja, "Study of the levels of some agricultural pollutants in soils and waterleaf (talinum triangulare) obtained in Maiduguri, Nigeria", J appl sci in environ sanit. 4 (2009) 71.

[15] Z. Monika \& M. Romic, "Soil contamination by trace metals. Geochemical behavior as an element of Risk assessment", earth and environmental sciences 8 (2011) 34. DOI: $10.5772 / 25448$

[16] United State Environmental Protection Agency, "Supplemental guidance for developing soil screening levels for superfund sites", Washington, D.C. (2002).

[17] C.M. Rochman, B.T. Hentschel \& S.J. Teh, “ Long-term sorption of 
metals is similar among plastic types: implications for plastic debris in aquatic environments", Environ. Sci. Technol. 47 (2013) 1646. http://dx.doi.org/10.1371/journal.pone.0085433

[18] M.R. Gregory, " Plastic "scrubbers" in hand cleansers: a further (and minor) source for marine pollution identified", Marine Pollution Bulletin
32 (1996) 867. https://doi.org/10.1016/S0025-326X(96)00047-1

[19] . L.M. Rios, C. Moore, \& P.R. Jones, " Persistent organic pollutants carried by synthetic polymer in the ocean environment", Mar. Pollut. Bull. 54 (2007) 1230. http://dx.doi.org/10.1016/j.marpolbul.2007.03.022. 